Marquette University

e-Publications@Marquette

College of Nursing Faculty Research and

Publications

Nursing, College of

$5-1-2000$

Relationship Between Scholastic and Health Behaviors and Reading Level in Adolescent Females

Steven C. Matson

Medical College of Wisconsin

Kristin Haglund

Marquette University, kristin.haglund@marquette.edu

Accepted version. Clinical Pediatrics, Vol. 39, No. 5 (May 2000): 275-280. DOI. (C) 2000 SAGE

Publications. Used with permission.

Kristin Haglund was affiliated with the Medical College of Wisconsin at the time of publication. 


\section{Relationship Between Scholastic and Health Behaviors and Reading Level in Adolescent Females}

By Steven C. Matson and Kristin A. Haglund

This was a study of 102 adolescent females, 12-20 years of age, presenting to a central city clinic for medical care. Participants completed an oral questionnaire that included demographics, and questions regarding scholastic history, sexual behavior, and substance use. Each subject completed the Accuracy Level Test (ALT), a reading test. The subject's reading test grade level was subtracted from her appropriate grade in school to give a reading delay level $(R D L)$. The mean reading grade level for all subjects was $6.7 \pm 2.6$ and the average reading delay was $4.5 \pm 2.5$ grades. Poor school attenders had greater reading delays (5.8 \pm 3.4 grades behind vs. $4.3 \pm 2.2$ for good attenders $p<0.04$ ), and those who repeated grades were also significantly delayed (5.5 \pm 2.4 grades behind vs. $3.7 \pm 2.3, p<0.0007$ ). Previously pregnant students had a greater delay in reading level than their nonpregnant peers (5.2 \pm 2.3 vs. $3.9 \pm 2.5$ respectively $p<0.01)$. Delayed reading levels appear to correlate with some risk behaviors. The ALT may serve as a tool to identify high-risk patients who need more intensive clinical intervention.

\section{Introduction}

Illiteracy is a significant problem in the United States and the world. Some data show that $10 \%$ of the U.S. population (15 million people) cannot read well enough to understand a newspaper or a letter from a teacher or friend. ${ }^{1}$ Another $20 \%$ are functionally illiterate, meaning they do not posses the literacy skills necessary to fulfill their own self-determined objectives as a family member, community member, citizen, consumer, or a member of social, religious, or other organizations. ${ }^{2}$ Illiteracy is most common among persons of low socioeconomic status. ${ }^{1,2} \mathrm{~A}$ group at high risk for illiteracy is low-income, single mothers. ${ }^{3}$ Although most illiterate U.S. adults are Caucasian, minority populations proportionally have higher rates. While $10-30 \%$ of the Caucasian population is functionally or marginally illiterate, the rate rises to $44 \%$ for AfricanAmericans and $56 \%$ for Hispanics. ${ }^{1,4}$ In considering the wide range of activities affected by poor reading skills, it seems logical that illiteracy may influence health as well. However, little published data exist regarding the relationship between reading ability and individual health and behavior. Studies of the relation between illiteracy and health outcomes in nonindustrialized countries have consistently shown the beneficial effect of increased reading skills. ${ }^{5}$ Studies may 
have shown a decrease in the infant mortality rate of $3.5 \%$ to $9 \%$ for each year of maternal education. ${ }^{6,7}$ Literate women were also more likely to use family planning services ${ }^{8,9}$ Further research has shown that patients with higher literacy skills were more likely to follow the instructions of their health care providers, ${ }^{10,11}$ more likely to keep chronic care appointments, ${ }^{12}$ and more likely to present for care early during illness. ${ }^{13}$

Delivering health care information to adolescents depends heavily on the written word. This assumes that most adolescents can read well enough to understand the information. Many providers assume that if adolescents are in a certain grade in school, for example 10th grade, they then can read and understand materials written at a $10^{\text {th }}$ grade level. In fact several studies have documented that reading level is often three to four levels below grade level. ${ }^{14-16} \mathrm{Health}$ care providers particularly depend on brochures for sensitive areas of health education such as sexuality, pubertal development, contraception, sexually transmitted diseases, and substance use. Unfortunately, the high-risk adolescents who need this information the most may be unable to read and understand the information.

The purpose of this study was to evaluate the usefulness of a rapidly administered reading test to identify delayed reading skills in a clinic setting. We were also interested in what relationships might exist between certain behaviors and delayed reading levels. This study specifically aimed to evaluate the utility of the Accuracy Level Test (ALT) in identifying patients with delayed reading levels and to identify relationships that exist between reading level and certain scholastic and health behaviors. We hypothesized that a history of poor school attendance, or experiencing a pregnancy, would be predictive of delayed reading levels.

\section{Methods}

This was a cross-sectional study using a convenience sample of 102 adolescent females, 11-20 years of age, presenting to a central city adolescent clinic in Milwaukee, WI, for health care over a 2-year period. The Research and Publications Committee/Human Rights Review Board of Children's Hospital of Wisconsin/ Medical College of Wisconsin reviewed and accepted the study protocol. The patients were asked to participate in the survey under the conditions that their answers and the overall results would be treated as confidential and anonymous. Participants were assured that the results would be kept confidential, results would not be placed in their clinic charts, and participation or refusal to participate would not affect their care as patients of the clinic. After permission was obtained: to participate in the study, patients were asked if they would like to complete the survey in the examination room while waiting to be seen or at the end of their visit. Upon completion of the survey, subjects were given two movie 
passes for their participation in the study. Each participant completed an oral questionnaire delivered by an investigator or one of two trained volunteers. The questionnaire included patient demographics and questions regarding school attendance, family scholastic achievement, sexual and contraceptive behavior, and use of cigarettes, alcohol, marijuana, and cocaine. Finally, each subject was given a timed 10- minute test of reading level (The Accuracy Level Test, Revrac Publications, Inc.). ${ }^{17}$ Each subject was given verbal instructions on how to complete the test and then given 10 minutes to finish. All subjects completed the test in the allotted time. The tests were then immediately scored and a raw reading score and grade equivalent level were recorded. The subject's reading level by itself would not identify poor readers. To identify subjects who were falling behind their peers we created the reading delay level (RDL). This was calculated by subtracting subjects' reading test grade level from their appropriate grade in school (determined by subtracting 5.5 from their age). For example, a 13.5year-old student would appropriately be in the 8th grade (13.5 - 5.5).

The Accuracy Level Test (ALT) is a 10-minute test containing 100 vocabulary words. The test measures the number of words an individual understands when reading. The raw score on the test can be used to derive a grade equivalent score and a vocabulary score. The grade equivalent score represents the most difficult reading material that an individual can read with at least 75\% comprehension. Possible grade equivalent scores range from grade one to grade 15 .

Comparison to other vocabulary tests has determined the validity of the ALT. The ALT correlated 0.82 with the vocabulary section of lowa Test of Basic Skills in grades seven and eight and correlated 0.77 with the vocabulary section of the Nelson-Denny Reading test with college students. ${ }^{18}$ Reliability was determined with the alternate form method yielding the standard error of measurement. The average alternate form reliability coefficient was 0.86 across grades three through college. This shows that the individual's grade equivalent score is reliable to within less than one grade level. ${ }^{18}$ To decrease the influence of isolated background experience, in which youth may not know the meaning of words owing to lack of familiarity (i.e., regional or cultural words) only adjectives and adverbs were selected, and nouns were excluded. Data were entered into a data base and analyzed by use of The Epi Info Version 6 computer program. ${ }^{19}$ Initially, descriptive statistics were calculated and recorded as percentages or means \pm 1 standard deviation. Correlational statistics were then calculated through use of Student's ttest and chi-square analyses. An alpha $<0.05$ and a beta=0.20 defined statistical significance. 


\section{Results}

There were 102 female subjects in this study. The mean age of participants was $16.6 \pm$ 1.8 years with a range from $12-20$ years of age. The majority were African- American (93\%) and $6 \%$ were Hispanic. Most were insured by a HMO-Medicaid program (63\%), $22 \%$ were non HMO-Medicaid, $11 \%$ were uninsured, and $4 \%$ had commercial insurance. The median grade of our subjects was 10 th with a range from 6 th to 15 th (two college students). The 25th to 75th percentiles went from 9th to 11th grade. School was regularly attended (4-5 days a week) by $84 \%$, and $43 \%$ had repeated at least one grade. Most participants (88\%) knew the highest level of school achieved by their mothers, whereas only 55\% knew the level attained by their fathers. Of those who knew their parents' scholastic history, $47 \%$ of the mothers and $61 \%$ of fathers had completed high school.

Only $14 \%$ of subjects reported alcohol use and $13 \%$ admitted smoking cigarettes. Marijuana was used by $38 \%$ of subjects and one subject noted cocaine use. Participants reported a high rate of sexual activity (86\%) with a mean age of sexual initiation of $14.3 \pm 1.5$ years, and 50 participants (49\%) had been pregnant at least once. While $77 \%$ of sexually active youth reported that they use condoms, only $37 \%$ noted perfect condom use in their last three sexual encounters and $27 \%$ reported no condom use at all.

Reading grade level test scores for this sample ranged from below 1st grade to 12th. The mean reading grade level for all subjects was $6.7 \pm 2.6$ as measured by the ALT. For 7th graders the average reading level was $4.4 \pm 2.1$ increasing to $6.6 \pm 2.9$ for 9 th graders and 8.7 \pm 2.0 for 12 th graders (Figure 1). The average reading delay (appropriate grade level for agemeasured reading level) was $4.5 \pm 2.5$ grades.

Non-HMO Medicaid subjects had a significantly greater reading delay (5.7 \pm 2.8 grades behind vs. $4.2 \pm 2.3, \mathrm{p}<0.01$ ) as compared with all other insurance types (Figure 2). Previously pregnant subjects had a greater delay in reading level than their nonpregnant peers (5.2 \pm 2.3 vs. $3.9 \pm 2.5$, respectively, $p<0.01)$. Students who did not regularly attend school had significantly greater reading delays than regular attenders (5.8 \pm 3.4 grades behind vs. $4.3 \pm 2.2$, respectively, $\mathrm{p}<0.04)$. Those who had repeated at least one grade had significantly greater reading delays compared with nonrepeaters $(5.5+2.4$ grades behind vs. $3.7 \pm 2.3$, respectively, $p<0.0007)$. Neither history of alcohol use or smoking nor other substance use was predictive of greater reading delay in our population. Neither contraceptive nor condom use was predictive of reading level. 


\section{Discussion}

Numerous studies have documented both poor reading skills in many clients and the impact that reading levels can have on the delivery of health-related services. Measuring literacy in a multiethnic sample of adult clients revealed that up to one third of the clients could not understand instructions for a routine procedure written at a 4th grade level; nearly one half were unable to understand the instructions on a medication bottle; one fourth were unable to understand written instructions for scheduling their next appointment; and more than half $(60 \%)$ could not understand a written informed consent. ${ }^{20}$ Another study conducted with adults revealed that the average reading comprehension level for adults attending public clinics was 6 th grade with $40 \%$ reading below a 5 th grade level. ${ }^{14}$ Adults in this study who attended private clinics had an average reading level of 10th grade. Much of the information given to patients is in written form, yet studies have documented that health materials are often above the patient's reading level. ${ }^{14-16}$ For instance, one study found a 10th grade mean reading level for commercially prepared contraceptive package inserts for condoms, diaphragms, and oral contraceptives. The mean reading level of similar materials prepared by providers of family planning services was 8 th grade. ${ }^{21}$ A study of HIV education materials ${ }^{22}$ revealed that the average reading level of materials was grade 9.9, with materials targeted toward adolescents at grade 8.3. Richwald et $\mathrm{al}^{23}$ found that eight of 12 condom package inserts required reading skills equivalent to those of a high school graduate. The simplest was at the 10th grade level.

This study documented poor reading levels in a population of adolescent females. The mean grade reading level of 6.7 is consistent with other reading level studies. ${ }^{15}$ Although most subjects attended school regularly, the average reading delay was more than four grades behind. Those students who were poor school attenders, had repeated grades, or had been pregnant were shown to have significantly greater reading delays. Our subjects who had been pregnant did not have a higher rate of repeated grades, which might explain the discrepancy. Students who are poor school attenders, have failed a grade, or are pregnant may be a population at high risk for serious reading deficits. Poor reading skills almost certainly affect many aspects of these teens lives. Note that much of the verbal and written information that we deliver to patients may be difficult to comprehend. This communication deficit leads to poorly informed patients and decreased success in prevention, health education, and treatment regimens. The ALT was easily administered and could become a standard part of a new patient visit. This would allow for increased time and resources going to adolescent clients with known reading delays. 
This study documents the poor reading ability of a subpopulation of adolescent females. Research findings show that these populations will have difficulty with basic written medical information. From these findings, we must consider and create educational materials for all adolescents. By doing so, all adolescents can understand, regardless of reading ability. We also need to understand the importance of taking extra time to explain examinations, laboratory tests, diagnoses, and treatment regimens. By ignoring this problem, we also ignore the consequences related to poor reading abilities among adolescent patients. Increased risks among adolescents with delayed reading skills include the inability to understand procedural directions, read prescriptions, or comprehend health information. Furthermore, teen mothers are included in this population. Typically, they are the primary educator and provider to their children. These mothers need basic written information and instruction so they in turn can administer the correct dosage of medication to their children, schedule immunizations, read a thermometer, or understand the contents of a consent form. By creating education materials specifically for adolescents we in turn are improving the delivery of high-quality patient care.

Since this is a cross-sectional study, we cannot show cause and effect. Future prospective studies will determine if poor reading skills predict health outcomes such as poor contraceptive use and pregnancy.

\section{References}

1. Kozol J. Illiterate America. Garden City, NY: Anchor Press/Doubleday; 1985.

2. Hunter CS, Harman D. Adult Illiteracy in the United States. New York: McGraw Hill; 1985.

3. Literacy and the Marketplace: Improving the Literacy Skills of Low-Income Single Mothers. New York: Rockefeller Foundation; 1989.

4. Hart G. Unlocking the Future: Adult Literacy in Arizona. Phoenix: Governors's and Superintendent's Joint Task Force on Illiteracy; 1986.

5. Weiss BD, Hart G, Pust RE. The relationship between literacy and health, J Health Care Poor Underserved, Vol 1, No. 4, Spring 1991.

6. Cochrane SH, O'Hara DJ, Leslie J. The effects of education on health. World Bank Staff Working Paper No. 405 Washington, DC: World Bank; 1980.

7. Socioeconomic Differentials in Child Mortality in Developing Countries. New York: United Nations Department of Social and Economic Affairs; 1985.

8. Coeytaux F, Donaldson D, Aloui T, et al. An evaluation of cost-effectiveness of mobile family planning services in Tunisia. Stud Fam Plann. 1989;20:158-169. 
9. Khan ME, Pressad CV. A comparison of 1970 and 1980 survey findings on family planning in India. Stud Fam Plann. 1985;16:312-320.

10. Nwote LO, Uwagboe PE, Madubuko GU. Evaluation of home-made saltsugar oral rehydration solution in a rural Nigerian population. J Trop Med Hyg. 1988;91:23-27.

11. Coreil J, Genece E. Adoption of oral rehydration therapy among Haitian mothers. Soc Sci Med. 1988:87-96.

12. Raghavia M, Bansal RD, Srinvasa DK, et al. Absenteeism in leprosy patients in a rural area in Tamil Nadu. Indian J Lepr. 1987;59:322-329.

13. Emembolu JO, Ekwempu CC. Carcinoma of the cervix uteri in Zaria: etiological factors. Int J Gynaecol Obstet. 1988;26:265-269.

14. Davis $T$, Crouch $M$, Wills $G$, et al. The gap between patient reading comprehension and the readability of patient education materials. J Fam Pract. 1990;31:533-538.

15. Doak LG, Doak CC. Patient comprehension profiles: recent findings and strategies. Patient Counsel Health Educ. 1980;2:101-106.

16. Powers R. Emergency department patient literacy and readability of patient- directed materials. Ann Emerg Med. 1988;17:124-126.

17. The Accuracy Level Test, Revrac Publications, Inc., Kansas City, MO.

18. Carver RP. Technical Manual for the Accuracy Reading Test, Revrac Publications, Inc., Kansas City, MO, 1987.

19. Epi Info Version 6. The Division of Surveillance and Epidemiology, Centers for Disease Control and Prevention, Atlanta, Georgia 30333.

20. Williams M, Parker R, Baker D, et al. Inadequate functional health literacy among patients at two public hospitals. JAMA. 1995;274:1677-1682.

21. Swanson J, Forrest K, Ledbetter C, et al. Readability of commercial and generic contraceptive instructions. Image. 1990;22:96-100.

22. Wells J, Ruscavage D, Parker B, McArthur L. Literacy of women attending family planning clinics in Virginia and reading levels of brochures on HIV prevention. Family Plann Perspect. 1994;26:113-115, 131.

23. Richwald G, Walmsley M, Coulson A, Moriskey D. Are condom instructions readable? Results of a readability study. Public Health Rep. 1988;103:355- 359. 


\section{Appendix}

\section{Figure 1}

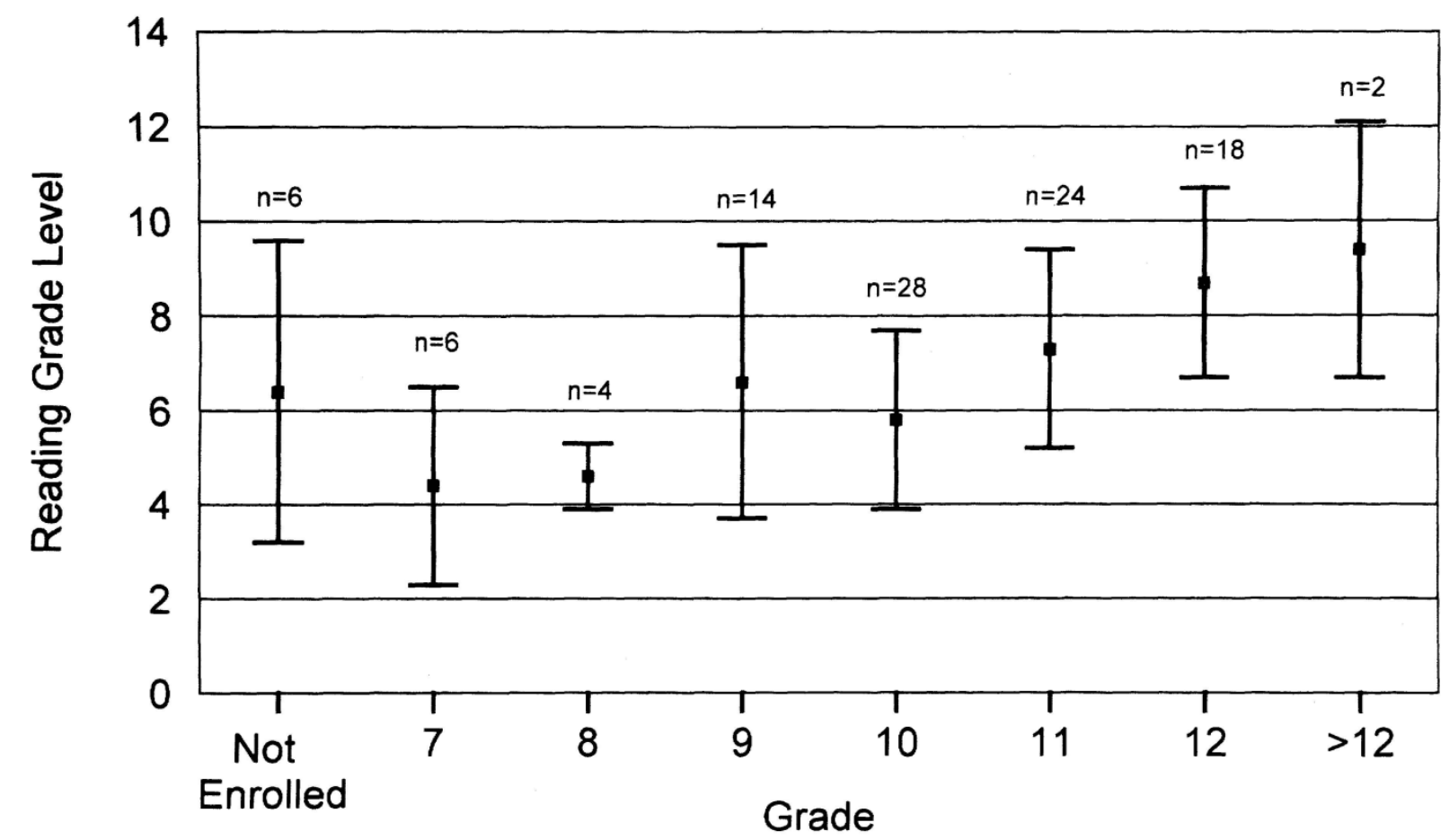

Actual tested reading levels (as measured by the Accuracy Reading Test) by students' grades in school. $\mathbf{\square}=$ mean \pm 1 SD. 
Figure 2

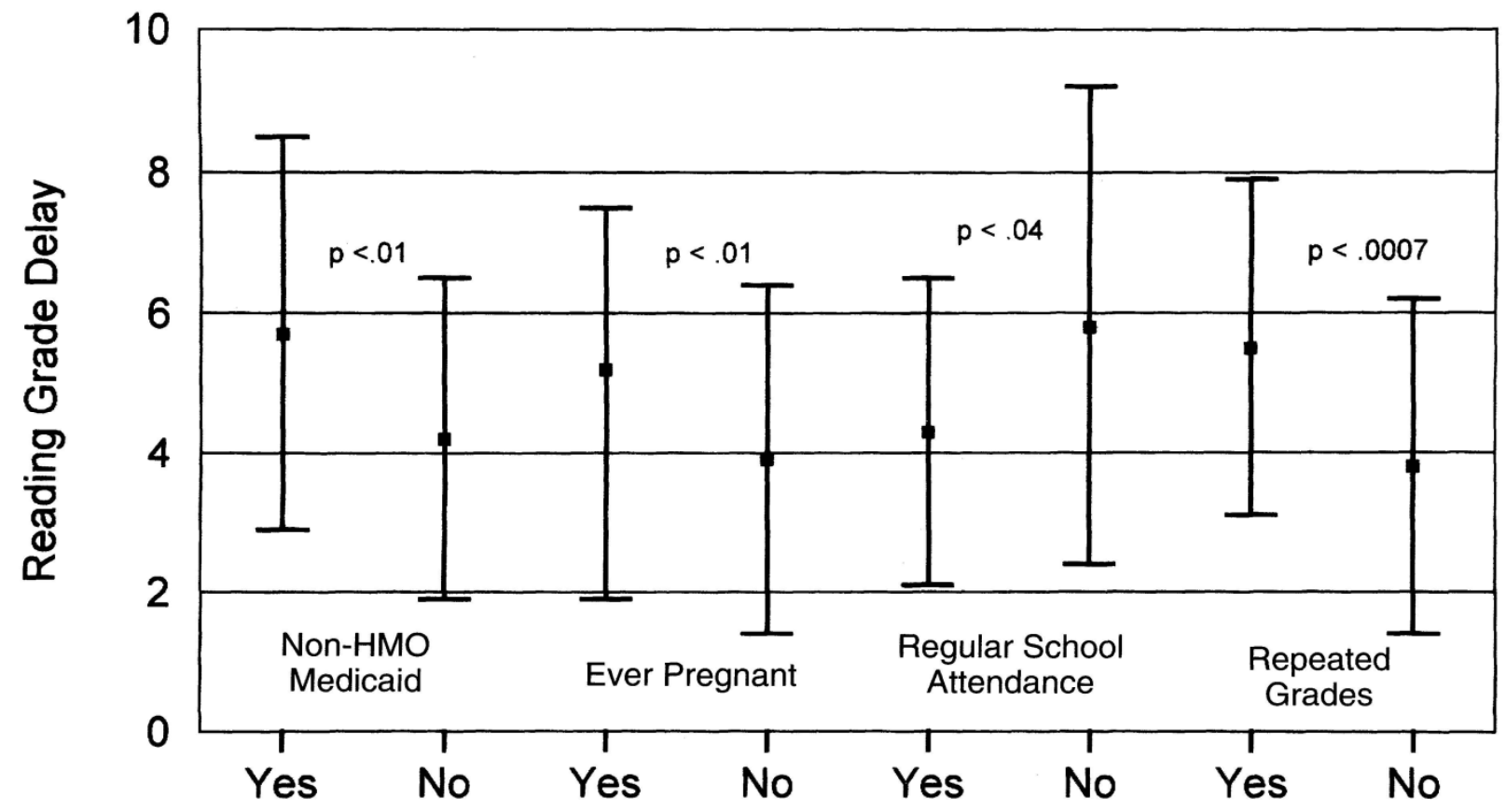

Relationships between several variables and reading delay level of subjects. $\mathbf{m}=$ mean \pm 1 SD . 